\title{
Projeto Interdisciplinar de Pesquisa e Aprendizagem - PIPA: realizando a inclusão da escola La Salle Pão dos Pobres na cultura digital
}

\author{
Anuar Daian de Morais - PPGIE/UFRGS - anuar_com_u@yahoo.com.br \\ Giovanni Biazzetto - IFCH/UFRGS - biazzetto@yahoo.com.br \\ Léa da Cruz Fagundes - PPGIE/PPGPSI/LEC/UFRGS - leafagun@ufrgs.br \\ Rafaela Silva - La Salle Pão dos Pobres - rafaela.silva @lasalle.edu.br
}

\section{Resumo}

Nesse artigo apresentamos uma discussão sobre a seguinte questão: Como realizar a inclusão da escola La Salle Pão dos Pobres na cultura digital para desenvolver o potencial criativo e o exercício da cidadania? Tal debate é realizado a partir dos dados coletados durante o desenvolvimento do Projeto Interdisciplinar de Pesquisa e Aprendizagem (PIPA) que ocorre desde 2010 nessa escola. Neste projeto educandos da quinta à oitava séries do ensino fundamental realizam pesquisas sob a perspectiva da metodologia de Projetos de Aprendizagem.

Palavras-chave: Inclusão Digital, Projetos de Aprendizagem, Aprendizagem em rede, Informática na Educação, Paradigma educacional Construtivista.

\begin{abstract}
In this paper we discuss the following question: How to make the inclusion of the La Salle Pão dos Pobres school in the digital culture to develop the creative potential and citizenship? This debate is conducted from data collected during the development of the Interdisciplinary Project for Research and Learning (IPRL) which occurs at the school since 2010. In this project students from fifth to eighth grade elementary school conduct research from the perspective of the Learning Projects of methodology.
\end{abstract}

Keywords: Digital Inclusion, Learning Projects, Network Learning, Informatics in education, constructivist educational paradigm.

\section{Introdução}

A escola La Salle Pão dos Pobres desenvolve um trabalho intitulado Projeto Interdisciplinar de Pesquisa e Aprendizagem, o PIPA. Através desse projeto, realizamos a inclusão digital de estudantes oriundos de comunidades carentes do município de Porto Alegre. Mas para entendermos melhor as inquietações que nos levaram a propor e a realizar o PIPA, é importante conhecer um pouco da história da escola La Salle Pão dos Pobres.

Os irmãos Lassalistas fazem parte da Fundação o Pão dos Pobres desde 1916. A partir dos anos 30, tal instituição passa a manter em regime de internato um grupo superior a 200 crianças e adolescentes órfãos e pobres, com a missão de ensiná-los, educá-los e profissionalizá-los. A partir de 2008 a Província Lassalista também assumiu a responsabilidade econômica e financeira da Escola, reformando-a e criando espaços educacionais como laboratórios de ciências, informática, biblioteca e etc. Dessa forma, além de atender os órfãos da Fundação o Pão dos Pobres, a escola passou a acolher crianças e jovens carentes da região do bairro Cidade Baixa. Sua capacidade de atendimento é de 450 alunos.

Sendo assim, desde março de 2010 a escola desenvolve o PIPA, a proposta desse trabalho surgiu durante a jornada de formação pedagógica, que é realizada 
anualmente. Nessa reunião, o assunto em questão era discutir alternativas para superar algumas dificuldades que o grupo de educadores e equipe diretiva vinham identificando, por exemplo: o baixo rendimento escolar e o desinteresse dos educandos em questões relacionadas ao conhecimento, a desvalorização da função da escola na sociedade.

Nesse contexto, ficamos nos questionando: qual escola desejamos para nossos educandos? Após algumas discussões, listamos algumas das características que essa escola deveria atender aos seguintes desejos:

1. Realizar a inclusão digital para desenvolver o potencial criativo e o exercício pleno da cidadania.

2. Desenvolver com os educandos e demais participantes do projeto o interesse pelo conhecimento.

3. Fomentar o desenvolvimento de um postura investigativa e, consequentemente, uma melhor compreensão da importância dos estudos para cada um(a).

4. Estabelecer relações de aprendizagem em rede através da utilização das TICs que promova uma mudança de paradigma educacional contribuindo, assim para a formação continuada dos professores e da comunidade escolar.

5. Promover o contato dos alunos com as técnicas básicas de pesquisa, possibilitando desenvolver também uma melhor organização para os estudos.

6. Promover a integração da Escola La Salle Pão dos Pobres com outras escolas e projetos.

7. Promover a integração da Comunidade Educativa La Salle Pão dos Pobres com a comunidade local.

8. Valorizar os alunos e demais participantes do projeto, suas ideias, expressões, vidas, histórias, conhecimentos, etc.

Em contraposição ao que desejamos, se refletirmos sobre a estrutura escolar vigente, podemos identificar que ela está baseada num modelo da cultura industrial. Nesse contexto, a escola possui a função de transmitir às novas gerações os conhecimentos culturalmente desenvolvidos e acumulados pela humanidade.

Para que essa transmissão seja potencializada, a educação passa a ter uma organização similar à linha de produção industrial, onde as áreas do conhecimento foram separadas e organizadas em disciplinas. Nessa lógica, temos um modelo de educação voltada para o ensino, em que cabe ao professor a função ativa de selecionar, organizar e transmitir o conhecimento, já aos alunos cabem o papel de recepção passiva daquilo que lhes é ensinado.

Ainda sobre esse aspectos podemos acrescentar o que diz Fagundes e seus colaboradores:

Os cursos convencionais tanto impõem quanto dependem de uma estrutura física, pedagógica e gerencial compartimentalizada e hierárquica. $\mathrm{O}$ espaço precisa ser subdividido em ambientes circunscritos a turmas de alunos que devem realizar nos mesmos espaços as mesmas atividades. O tempo é subdividido em períodos sequenciais numa grade de horários que impede a interdisciplinaridade, e onde a espinha dorsal é a exploração de "conteúdos programáticos" disciplinares. (FAGUNDES et al, 2006)

Em contrapartida a esses fatos, no prefácio do livro $O$ computador Portátil na Escola, o prof. Ubiratan Dambrósio afirma que a escola é para os alunos um ambiente irreal, visto que os meios digitais estão tão presentes na nossa cultura que o que não é 
digital, é fantasia. Dessa forma, para ele a educação deve ser reconceituada e seguir dois objetivos maiores:

1) Dar oportunidade para que todos desenvolvam seu potencial criativo.

2) Preparar as novas gerações para o exercício pleno de cidadania.

Ainda acrescenta que nenhum desses objetivos podem ser atingidos sem a plena inclusão digital (2011, p. 09).

\subsection{Caracterização do Problema}

A partir das inquietações e dos desejos apresentados na secção anterior, a questão que propomos discutir nesse artigo é: Como realizar a inclusão da escola La Salle Pão dos Pobres na cultura digital para desenvolver o potencial criativo e o exercício da cidadania? Ressaltamos a importância dessa questão, visto que ela foi a pergunta que norteou (e norteia) as ações realizadas no PIPA.

Além disso, pensamos que essa ainda é uma discussão necessária, visto que as dificuldades relatadas e o desejo de modificação na dinâmica da nossa escola, estão presentes em diversas instituições de ensino.

\section{Fundamentação Teórica}

Muitos pesquisadores apontam que o uso das Tecnologias da Informação e Comunicação (TICs) estão transformando nossa sociedade e, consequentemente, a Educação. Dentre elas, a internet é a ferramenta tecnológica que se destaca. Através dela acompanhamos o surgimento de uma cultura em rede e, em função dessa nova forma de se organizar, pensamos que a cultura escolar também deve se transformar para um modelo mais dinâmico e interativo: um modelo fomente a aprendizagem em rede. Um exemplo desse fato é a ampla disseminação de cursos na modalidade EaD.

Por consequência, torna-se importante pesquisar quais são as metodologias disponíveis que atendem às necessidades dessas novas demandas. Mais quais são essas necessidades?

\section{Segundo NEVADO, CARVALHO E MENEZES}

(...) a EAD pressupõe que pensar, experimentar, avaliar divulgar sejam ações que se realizam em todos os momentos da existência da pessoa e se, de um lado, prescinde de tempos e espaços fechados, de outro, é fundamental a troca entre os sujeitos que, em comunidades de aprendizagem, conferem sentido ao que se denomina conhecimento situado. (NEVADO, CARVALHO E MENEZES, 2005, p. 10)

$\mathrm{Na}$ nossa avaliação essa pressuposição não é exclusividade da EAD, mas da educação como um todo, pois as trocas entre os sujeitos em comunidades de aprendizagem são fundamentais, seja na modalidade à distância ou presencial.

Essa ideia não é nova, Piaget (1947) afirmou que a interação social é indispensável para que a criança desenvolva uma lógica, já que "A criança procura evitar contradizer-se em presença de outras pessoas" (PIAGET apud KAMII, 1986, p. 51). Além disso, é a partir da interação social que qualquer pessoa entra em contato com diferentes pontos de vista que podem gerar o que Piaget chamou de Conflito Cognitivo. Portanto, é o contexto social que incentiva o sujeito a pensar sobre os outros pontos de vista em relação ao seu próprio, constituindo-se num processo de descentração que é fundamental para o desenvolvimento lógico-matemático, moral e social.

Sendo assim, as TICs propõem um novo paradigma social e educacional. Para Fagundes "estamos vivendo um processo de rápidas transformações nas formas de ser, 
viver, relacionar-se. (...) Torna-se quase impossível planejar e definir com antecedência o que deve ser aprendido e que competências são necessárias para habitar esse "mundo novo" (1999, p. 13).

Então, a sociedade exige sujeitos criativos, autônomos, cooperativos, capazes de interpretar e resolver problemas em diferentes situações não previsíveis. Por conseguinte, a escola precisa adequar-se a tal contexto e, portanto, passar de um modelo baseado na reprodução de conhecimento, para um modelo de produção de conhecimento. Conforme Costa, Fagundes e Nevado

(...) a educação não pode apenas ocupar o papel de transmissão de informações valores, nem o professor de agente dessa transmissão, nem as TICs podem ser vistas como ferramentas para "otimizar" a transmissão ou a gestão da informação. É necessário, portanto, uma proposta heurística e construtiva para expansão das capacidades individuais e grupais e um novo modelo na formação de professores (COSTA, FAGUNDES, NEVADO p. 02, 1998).

Avaliamos que a concepção educacional construtivista atende às necessidades dessa nova cultura digital. Pois nessa perspectiva o conhecimento não é algo fixo e acabado, ele surge de um contexto de trocas e de um processo de reflexões sobre aquilo que se conhece e o que se quer conhecer.

Isso significa dizer que não é apenas a utilização dos computadores e das TICs que irá garantir uma mudança educacional voltada para o desenvolvimento da autonomia e do potencial criativo dos indivíduos. Mas seu uso deve estar relacionado a uma proposta pedagógica que leve esses aspectos em consideração.

Nesse sentido pensamos que a metodologia de projetos de aprendizagem pode promover a mudança para um paradigma educacional de aprendizagem, já que é um modelo mais dinâmico de construção de conhecimento. Segundo Fagundes:

A situação de projeto de aprendizagem pode favorecer especialmente a aprendizagem de cooperação, com trocas recíprocas e respeito mútuo. Isto quer dizer que a prioridade não é o conteúdo em si, formal e descontextualizado. A proposta é aprender conteúdos, por meio de procedimentos que desenvolvam a própria capacidade de continuar aprendendo, num processo construtivo e simultâneo de questionar-se, encontrar certezas e reconstruí-las em novas certezas. Isto quer dizer: formular problemas, encontrar soluções que suportem a formulação de novos e mais complexos problemas. Ao mesmo tempo, este processo compreende o desenvolvimento continuado de novas competências em níveis mais avançados, seja do quadro conceitual do sujeito, de seus sistemas lógicos, seja de seus sistemas de valores e de suas condições de tomada de consciência. (FAGUNDES, NEVADO, CARVALHO e MENEZES, p.30, 2005).

Dessa forma, o papel do professor e do estudante também deve se transformar, segundo Nevado, Carvalho e Menezes

Ao professor cabe a função de promover a aprendizagem, estimular o diálogo, provocar a emergência de situações de dúvidas (desequilíbrios) e apoiar as reconstruções (novos conhecimentos. Ao aluno cabe uma postura ativa. A ele cabe experimentar, compartilhar, criar, interagir para compreender. (FAGUNDES e MAÇADA, 1999).

Sendo assim, após conhecer tal proposta a partir do projeto AMORA do Colégio de Aplicação da UFRGS, o grupo de educadores aceitou o desafio de implementar na escola La Salle Pão dos Pobres a metodologia de Projetos de Aprendizagem (PA) nas turmas de quinta à oitava série do ensino fundamental. Acreditando que tal metodologia 
possibilitava a implementação da escola que desejávamos através de um processo de inclusão digital.

Mas o que são PAs? São pesquisas que os educandos realizam a partir de uma questão norteadora (um problema, uma curiosidade) formulada por eles próprios, segundo Fagundes, Sato e Maçada:

"Um projeto para aprender vai ser gerado pelos conflitos, pelas perturbações nesse sistema de significações, que constituem o conhecimento particular do aprendiz (...) o aprendiz é desafiado a questionar, quando ele se perturba e necessita pensar para expressar suas dúvidas, quando lhe é permitido formular questões que tenham significação para ele, emergindo de sua história de vida, de seus interesses, seus valores e condições pessoais, passa a desenvolver a competência para formular e equacionar problemas. (p. 16, 1999).

Tal metodologia foi desenvolvida a partir de pesquisas desenvolvidas no Laboratório de Estudos Cognitivos (LEC/UFRGS).

\section{Resultados e Discussão}

Sob a coordenação dos professores da escola (e autores deste artigo) Anuar D. Morais, Giovanni Biazzetto e Rafaela da Silva, o PIPA foi executado em duas etapas: no primeiro semestre de 2010 foi realizada uma formação com os educadores da escola, já no segundo semestre, os educandos iniciaram seus projetos de aprendizagem.

Quanto a formação dos educadores, inicialmente identificamos que, dos dezessete membros da equipe pedagógica, nove possuíam alguma experiência com blogs, um já tinha trabalhado com wikis e oito nuca haviam explorado tais ferramentas. Sendo assim, era fundamental que os professores recebessem uma formação para aprender a utilizar o Pbworks, visto que tal ferramenta seria utilizada com os educandos.

Além disso, não podemos ser ingênuos e acreditar que a simples utilização das TICs seria suficiente para transformar - sozinhas - as concepções dos professores e refletir diretamente no processo de aprendizagem dos alunos. Era importante criar para os educadores um espaço para a formação e reflexão de sua prática. Segundo Basso

"Pensar que mudanças - necessárias - na Escola ocorrerão a partir da implantação de ambientes informatizados, com acesso a recursos de Educação à Distância, sem considerar como básico a formação de usuários e produtores de conhecimento, redunda no fracasso" (p. 03, 1999).

Tendo consciência desse fato, propomos que os educadores também realizassem seus próprios projetos de aprendizagem com o objetivo de vivenciar o mesmo processo de aprendizagem dos educandos. Sendo assim, a publicação de suas pesquisas no Pbworks foi consequência da necessidade de divulgar e realizar trocas com os colegas.

Dessa forma invertemos a lógica presente nos cursos convencionais; não foi oferecido um curso de Pbworks aos educadores, eles aprenderam uma ferramenta em função de uma necessidade, dando significado a essa ação. Pensamos que tal concepção já representa um pequena modificação de concepção educacional, voltada para a aprendizagem.

\subsection{Formação Continuada dos Educadores via Projetos de Aprendizagem}

As pesquisas desenvolvidas pelos professores estão publicadas no seguinte endereço: http://projetoslasallepdp.pbworks.com. 
O gráfico abaixo, foi construído a partir dos recursos utilizados nas páginas dos projetos dos educadores.

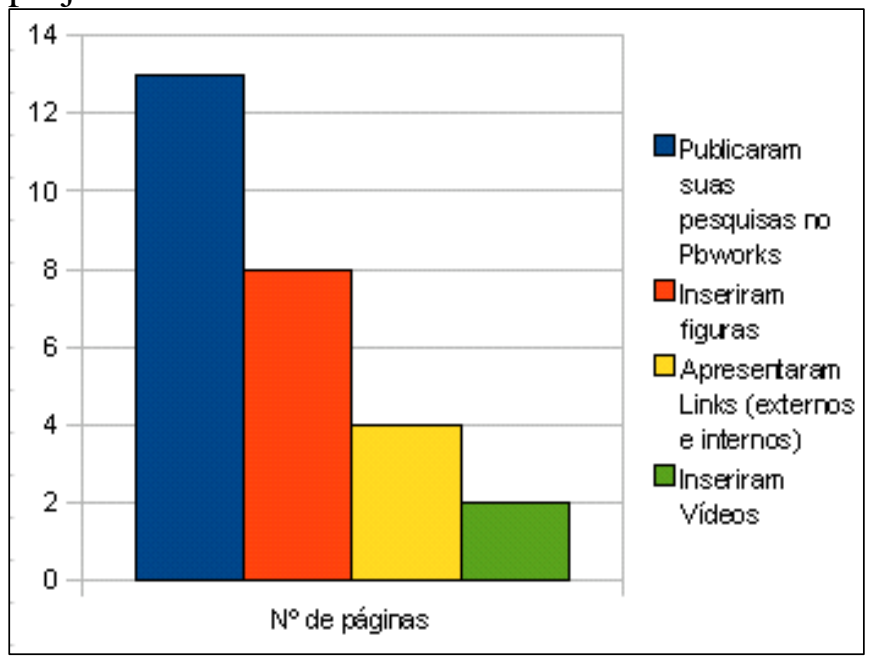

Podemos observar que dos dezessete educadores, aproximadamente:

1) $76 \%$ dos construíram suas páginas.

2) $47 \%$ colocaram imagens nas suas páginas,

3) $23,5 \%$ fizeram uso de links externos ou internos.

4) $11,7 \%$ inseriram vídeos nas suas páginas.

Ao analisarmos esses itens podemos concluir que os educadores também estão num processo de alfabetização digital em relação as TICS. Visto que $24 \%$ dos educadores não produziram páginas no Pbworks, daqueles que produziram: $39 \%$ não fizeram uso de imagens, portanto seu conteúdo era apenas texto e $69,2 \%$ produziram textos lineares, onde não havia links.

Isso indica que a produção deste grupo de educadores ainda está voltada para o uso das linguagens características da sociedade industrial, onde o texto tem lugar de destaque, deixando de explorar, assim, a linguagem icônica e hipertextual que as TICs permitem e que estão presentes no cotidiano das novas gerações. Tal fato indica que o processo de inclusão na cultura digital não é voltado apenas para os educandos, mas para toda escola La Salle Pão dos Pobres.

Por outro lado, estaríamos sendo injustos com os educadores, se não levarmos em consideração os seguintes aspectos: a) infelizmente a maior parte da formação foi realizada à distância, com trocas via grupo de e-mail. b) $\mathrm{O}$ espaço de exploração no Pbworks ficou restrito à dois encontros presenciais de uma hora de duração cada. c) as máquinas disponíveis no laboratório de informática da escola são antigas e lentas.

Tais fatores atrapalharam a produção daqueles educadores que possuíam uma jornada semanal de trabalho superior a 40 horas, bem como aqueles que estavam tendo o seu primeiro contato com tais ferramentas. Além disso, sabemos que todos educadores utilizam os recursos do Office para produzirem seu material pedagógico e se comunicam periodicamente através do e-mail da escola, portanto a utilização das TICs já faz parte do seu cotidiano e não estamos partindo de um estágio mais inicial.

Apesar dessas dificuldades a equipe pedagógica manteve-se motivada a realizar o lançamento do PIPA, onde alguns educadores apresentaram seus projetos de aprendizagem para os educandos.

\subsection{Modificando a estrutura da Escola}

Nossa escola possui treze educadores para atender todas as disciplinas de $5^{\circ}$ a $8^{\circ}$ série do ensino fundamental, no entanto o grupo inteiro não está disponível todos os dias da semana, visto que a grande maioria trabalha em outras instituições de ensino. Sendo assim, nos deparamos com o seguinte problema: Como poderíamos organizar um horário que permitisse a interdisciplinariedade? Diante desse desafio construímos a seguinte proposta:

1) O PIPA ocorreu em dois períodos por semana. 
2) Na primeira semana ele ocorreu na sexta-feira; na semana seguinte, na quinta-feira; na seguinte, na quarta-feira e assim por diante.

3) Além disso os períodos também deveriam alternar, visto que na primeira semana $o$ encontro ocorreu nos $2^{\circ}$ e $3^{\circ}$ períodos, na semana seguinte, nos $4^{\circ}$ e $5^{\circ}$ períodos e assim sucessivamente. Como exemplo, veja a tabela 01 .

Com tal proposta, possibilitamos que todos os educadores tivessem oportunidade de acompanhar e orientar as pesquisas dos educandos periodicamente, inclusive aqueles educadores que vinham na escola apenas duas vezes na semana.

Ainda para garantir a interdisciplinaridade, o grupo de educadores foi dividido em duplas de diferentes áreas do conhecimento. Sendo assim, após decidirem qual seria o assunto de suas pesquisas, os educandos foram reorganizados em seis grupos de interesse.

No entanto ainda havia mais fato a ser considerado, para que a inclusão digital ocorresse efetivamente, precisávamos aumentar o acesso dos educandos ao laboratório de informática. Sendo assim, deveríamos estudar novas alternativas para que isso acontecesse, já que na escola há apenas um laboratório de informática com vinte máquinas.

Desse desafio, surgiu o estabelecimento de uma parceria coma a Fundação Pão dos Pobres (a primeira do PIPA). Tal instituição mantém uma série de cursos profissionalizantes que ocorrem no turno da noite. Como eles não estavam sendo

\begin{tabular}{|c|c|c|}
\hline MÊS & LABIN. INFO & PERÍODO \\
\hline \multicolumn{3}{|c|}{ SETEMBRO } \\
\hline 07/ter & $C, D, E$ e F & $4^{\circ}$ e $5^{\circ}$ \\
\hline $13 /$ seg & $A, B, C$ e D & $2^{\circ} \mathrm{e} 3^{\circ}$ \\
\hline $24 / \operatorname{sex}$ & $E, F, A$ e B & $2^{\circ} \mathrm{e} 3^{\circ}$ \\
\hline $30 /$ qui & C, D E e F & $4^{\circ}$ e $5^{\circ}$ \\
\hline \multicolumn{3}{|c|}{ Tabela 01: Horário do PIPA em setembro de 2010} \\
\hline
\end{tabular}

$01)$. utilizados no turno da manhã, a fundação disponibilizou dois laboratórios com 25 computadores e uma sala com 5 máquinas. Sendo assim, a cada encontro do PIPA quatro grupos de estudantes utilizaram o computador para pesquisar e produzir os seus projetos de aprendizagem (Tabela

A partir dos aspectos acima citados, pensamos que o PIPA realmente possibilitou uma reestruturação da escola ao desenvolver um modelo mais dinâmico. Veja bem, uma vez por semana a escola La Salle Pão dos Pobres se organizava de uma maneira totalmente nova, onde educandos de diferentes idades estavam agrupados a partir de seus interesses de pesquisa. Mesmo que tivessem ocupando o mesmo espaço físico, não estavam realizando as mesmas atividades. Além disso, eram orientados por dois educadores que não tinham a função de transmitir conhecimento, mas orientá-los na sua pesquisa, problematizando e promovendo o debate. Ou seja, a escola era um espaço propício ao desenvolvimento da interdisciplinariedade e do processo criativo dos educandos. E tudo isso era mediado pelas TICs através de uma inclusão digital. Como afirma Valente:

Somente implantar ou prover acesso aos computadores ou laptops não vai alterar a maneira como a educação é desenvolvida, muito menos que essa tecnologia tenha um impacto significativo na performance dos alunos. Os computadores só fazem sentido se forem implantados para enriquecer o ambiente de aprendizagem e se nesse ambiente existir as condições para favorecer o aprendizado de cada aluno. Nesse, caso os 
computadores são extremamente importantes para a criação dessas condições - eles passam a ser necessários como um instrumento musical para produzir música! (VALENTE in BAGATINI e ALMEIDA, 2011, p. 22).

Dessa forma, o PIPA é um espaço que visa dar oportunidade para que todos desenvolvam seu potencial criativo, preparando as novas gerações para o exercício pleno de cidadania.

\subsection{A alfabetização digital via projetos de aprendizagem}

Durante o segundo semestre de 2010, os educandos da escola La Salle Pão dos Pobres, desenvolveram 175 projetos de aprendizagem que estão disponíveis no seguinte endereço eletrônico: http://palasallepdp.pbworks.com/.

Logo nos primeiros encontros identificamos que a primeira etapa do trabalho seria voltada para a alfabetização digital dos educandos. Visto que grande parte das crianças não tinham acesso ao computador, nem à internet e, por consequência, não tinham e-mail. Sendo assim, nas duas primeiras semanas realizamos um mutirão para criar o e-mail pessoal dos estudantes.

Nesse processo um fato nos chamou a atenção, havia aqueles estudantes que tinham acesso periódico à internet, participavam de redes sociais e utilizavam o Msn para se comunicar com amigos. No entanto, ao serem questionados se tinham e-mail afirmavam: "E-mail não tenho, serve msn?" Quando dizíamos à eles, que se tinham msn, também possuíam e-mail, expressavam surpresa.

Após o mutirão, os educandos começaram a construir suas páginas no Pbworks. Para auxiliar os educadores nesse processo, os estudantes da oitava série desempenharam a função de monitores. Seu dever era auxiliar na resolução de problemas referente a utilização do Pbworks. Nossa intenção com essa atitude era a promover uma postura de cooperação entre os educandos e dar continuidade ao processo de apropriação do Pbworks pelos educadores.

\subsection{Avaliação dos Projetos de Aprendizagem dos Educandos.}

Levando em consideração o caráter interdisciplinar do PIPA, sabíamos que a avaliação dos PAs valeria para todas as disciplinas. Nesse sentindo o grupo de educadores estipulou que, dois pontos da avaliação total do trimestre, seria destinado ao projeto.

No nosso entendimento esse é um aspecto contraditório com a proposta de Projetos de Aprendizagem. Afinal de contas, como podemos mensurar a aprendizagem dos educandos se eles estão realizando atividades diferentes e estão em níveis de aprendizagem diferentes?

Temos consciência que tal questão merece um debate mais detalhado, no entanto tal discussão é mais delicada, visto que não envolve apenas a escola La Salle Pão dos Pobres, mas o plano pedagógico da rede La Sallista.

Diante dessa realidade, decidimos criar estratégias para realizar uma avalização de caráter mais qualitativo possível. Dessa forma, produzimos o seguinte instrumento de avaliação:

Durante a realização de seu Projeto de Aprendizagem o estudante:

1) Colaborou para o bom desenvolvimento do projeto e cooperou com colegas 
professores; Demonstrou uma postura investigativa e, semanalmente, buscou/ apresentou novas informações sobre sua pesquisa.

2) Texto autoral e identificou as fontes de pesquisa;

3) Apresentou conclusão com base na sua pesquisa e apresentou glossário.

4) Organização da página (formatação, ortografia, imagens, vídeos...)

Cabendo ao educador atribuir um valor de 0,1 à 0,5 pontos para cada critério apresentado.

Para o encerramento do primeiro ano de PIPA, realizamos uma espécie de Salão de Iniciação Científica, onde cada educando apresentou pesquisa. $\mathrm{O}$ evento durou a semana inteira, ocorreu nos três primeiros períodos da manhã e era aberto ao público.

As apresentações ocorreram simultaneamente em três espaços diferentes e foi organizada da seguinte forma: Num primeiro momento, os pesquisadores escolheram o local que gostariam de realizar a apresentação do seu projeto de aprendizagem. Após a divulgação da lista de apresentação, os demais estudantes escolheram quais apresentações tinham interesse em assistir.

Cada estudante tinha 15 minutos para apresentar sua pesquisa e ser questionado por uma banca. Tal banca era composta por dois educadores e dois educandos que eram escolhidos naquele momento.

Dessa experiência, concluímos que o potencial criativo e a postura investigativa são desenvolvidos durante a confecção dos projetos de aprendizagem. No entanto, o exercício de cidadania é promovido nesse momento, em que cada educando apresenta e defende suas ideias, sendo respeitado e ouvido por seus colegas.

\begin{abstract}
“(...) Se o objetivo é formar alguém que procure resolver conflitos pelo diálogo, deve-se proporcionar um ambiente social em que tal possibilidade exista, onde possa, de fato, praticá-lo. Se o objetivo é formar um indivíduo que se solidarize com os outros, deverá poder experienciar o convívio organizado em função desse valor. Se o objetivo é formar um indivíduo democrático, é necessário proporcionar-lhe oportunidades de praticar a democracia, de falar o que pensa e de submeter suas ideias e propostas ao juízo de outros. Se o objetivo é que o respeito próprio seja conquistado pelo aluno, deve-se acolhê-lo num ambiente em que se sinta valorizado e respeitado. Em relação ao desenvolvimento da racionalidade, deve-se acolhê-lo num ambiente em que tal faculdade seja estimulada. A escola pode ser esse lugar.(...)" ( PCN, Vol. 08, pág. 87).
\end{abstract}

A postura de respeito e compromisso apresentada pelos educandos durante a semana de apresentação dos projetos de aprendizagem, foi observada e comentada durante as avaliações pelo grupo de educadores do La Salle Pão dos Pobres. A satisfação foi tanta que a equipe pedagógica decidiu dar continuidade ao PIPA em 2011.

Além disso, atualmente contamos com mais apoio da escola, temos encontros periódicos voltados para a formação dos educadores, três horas semanais voltadas a coordenação do PIPA e pretendemos estendê-lo as séries iniciais do ensino fundamental. Tais fatos evidenciam que o PIPA está crescendo e se expandindo.

\title{
4. Conclusão
}

Retomando a questão apresentada no início desse trabalho: Como realizar a inclusão da escola La Salle Pão dos Pobres na cultura digital para desenvolver o 
potencial criativo e o exercício da cidadania? Após apresentarmos e refletirmos sobre as ações realizadas no PIPA, avaliamos que o potencial criativo e o exercício da cidadania se desenvolve a medida que o processo de inclusão digital evolui e viceversa.

No entanto, para que isso ocorra é necessário que a utilização do computador tenha como objetivo enriquecer o ambiente de aprendizagem e nesse ambiente devem existir as condições necessárias para favorecer o aprendizado de cada aluno. Na nossa análise, essas condições necessárias são promovidas quando a utilização dos computadores está relacionada à metodologia de projetos de aprendizagem.

Por enquanto, supomos que a mudança de paradigma educacional de aprendizagem ocorre na medida que esses processos evoluem e se coordenam entre si. No entanto, são necessários mais estudos par poder confirmar tal afirmação.

Por fim, gostaríamos de registrar que o desenvolvimento do PIPA não foi sempre tranquilo; pelo contrário, passamos por muitas dificuldades, momentos de estagnação, incertezas e conflitos de ideias. Todavia, temos consciência de que isso é um processo natural da atividade cognitiva de desenvolver projetos. Diante disso, identificamos três aspectos que merecem ser estudados.

1) Utilizar as TICs para realizar trocas entre educadores e educandos de outras escolas que utilizam projetos similares ao PIPA, formando, assim, uma comunidade em rede.

2) Utilizar a teoria de Mapas conceituais para avaliar a aprendizagem dos educandos sob uma perspectiva construtivista.

3) A tendência dos educadores entenderem as atividades do PIPA como mais uma disciplina e que, na maioria das vezes, não relação com a sua área de conhecimento.

\section{Referências Bibliográficas}

1. BAGATINI, Fátima Maria, e ALMEIDA, Maria Elizabeth... [et al]: O computador portátil na escola: mudanças e desafios nos processos de ensino e aprendizagem. Avercamp, São Paulo, 2011.

2. BASSO, Marcus Vinicius de A. et al.; Educação Tecnológica e/ na Educação Matemática: Aplicações da Matemática Elementar na Sala de Aula. Revista Informática na Educação - Teoria e Prática. Universidade do Rio Grande do Sul. Porto Algre. Outubro. 1999.

3. BRASIL. Parâmetros Curriculares Nacionais. Ética . Brasília: MEC/SEF, 1998.

4. COSTA, I. T.; FAGUndes, L. C.; NEVADO, R. A.: Projeto TecLec: Modelo de uma Nova Tecnologia em EaD incorporando os Recursos da Telemática" . Em: Informática na Educação: Teoria \& Sociedade, v. 63, p. 105 -111, 1998.

5. FAGUNDES, L. ; SATO L. S.; MAÇADA, D. L. Aprendizes do futuro: as inovações começaram. Brasília: MEC, 1999. Coleção Informática para a Mudança em Educação/Mec/Seed/Proinfo.

6. FAGUNDES, Léa da Cruz; ARAGÓN DE NEVADO, Rosane; BASSO, Marcus Vinicius de Azevedo, BITTENCOURT, Juliano de Vargas; MENEZES, Crediné Silva de, MONTEIRO, Valéria Cristina: Projetos de aprendizagem: uma experiência mediada por ambientes telemáticos. Revista brasileira de informática na educação. Vol. 14, n. 1 (jan./abr. 2006), p. 29-39.

7. PIAGET, Jean, INHELDER, Bärbel. Gênese das Estruturas Lógicas Elementares. Editora Zahar, Riode Janeiro, 1975.

8. PIAGET, Jean. Psicologia e epistemologia genética. Editora Forense, Rio de Janeiro, 1973. 